\title{
Prediction of bending load capacity of timber beams using a finite element method simulation of knots and grain deviation
}

\author{
V. Baño ${ }^{a, *}$, F. Arriaga $^{b}$, A. Soilán ${ }^{c}$, M. Guaita ${ }^{d}$ \\ ${ }^{a}$ CETEMAS, Centro Tecnológico Forestal y de la Madera, Finca Experimental La Mata s/n, 36820 Asturias, Spain ${ }^{1}$ \\ ${ }^{b}$ Escuela Técnica Superior de Ingenieros de Montes, Polytechnic University of Madrid, Ciudad Universitaria s/n, 28040 Madrid, Spain ${ }^{2}$ \\ ${ }^{c}$ CIS Madeira, Centro de Innovación e Servizos da Madeira, Avda. Galicia, Parque Tecnolóxico de Galicia, E-32901, San Cibrao das Viñas, \\ Ourense, Spain ${ }^{3}$ \\ ${ }^{\mathrm{d}}$ Universidade de Santiago de Compostela, Dpto. Ingeniería Agroforestal, C/Benigno Ledo s/n, 27002 Lugo, Spain ${ }^{4}$
}

\begin{abstract}
A finite element model was used to simulate timber beams with defects and predict their maximum load in bending. Taking into account the elastoplastic constitutive law of timber, the prediction of fracture load gives information about the mechanisms of timber failure, particularly with regard to the influence of knots, and their local grain deviation, on the fracture. A finite element model was constructed using the ANSYS element Plane42 in a plane stress $2 \mathrm{D}$-analysis, which equates thickness to the width of the section to create a mesh which is as uniform as possible. Three sub-models reproduced the bending test according to UNE EN 408: i) timber with holes caused by knots; ii) timber with adherent knots which have structural continuity with the rest of the beam material; iii) timber with knots but with only partial contact between knot and beam which was artificially simulated by means of contact springs between the two materials. The model was validated using ten $45 \times 145 \times 3000 \mathrm{~mm}$ beams of Pinus sylvestris L. which presented knots and grain deviation. The fracture stress data obtained was compared with the results of numerical simulations, resulting in an adjustment error less of than $9.7 \%$.
\end{abstract}

\section{Introduction}

Visual strength grading for structural sawn timber considers, among other singularities, the presence and size of knots, fissures, wanes and grain deviation; however the most relevant are knots and the deviation of grain.
Structural timbers present knots and local deviation of grain in the area surrounding the knots. Stresses are calculated assuming the homogeneity and isotropy of the material but the true behaviour of the timber is more complex. When a knot is located in the tension side of a beam, the local grain deviation produces in the fibres, not only tension parallel to 


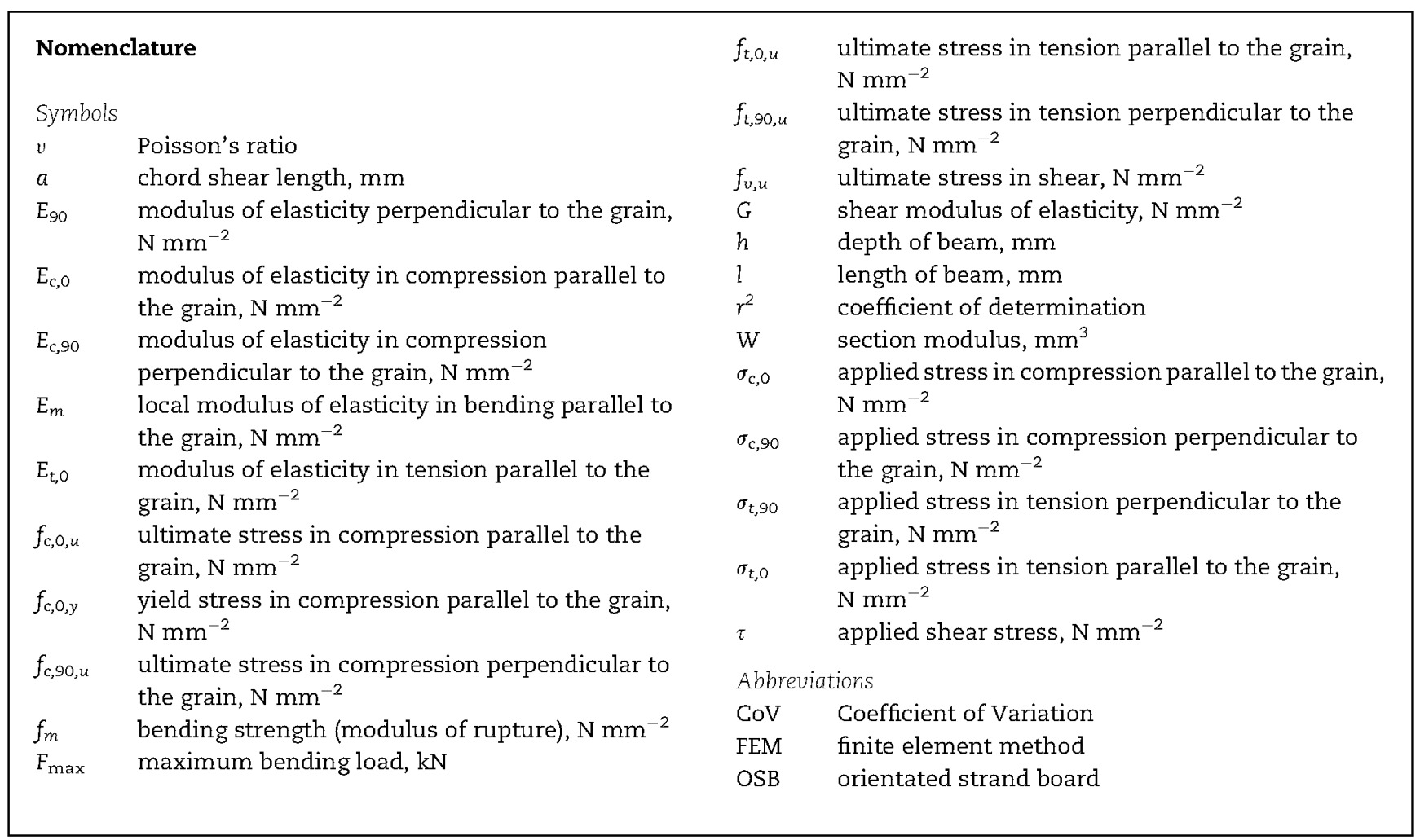

the grain stresses, but also perpendicular to the grain and shear stresses (Fig. 1). Therefore, prior to maximum load being reached partial ruptures are produced. Usually, the rupture begins with a fissure due to tension perpendicular to the grain around the knot together with tension parallel to the grain. This level of stress, with large knots, usually occurs in the elastic phase, and it is possible to analyse the strength of the beam applying the theory of strength of materials. When the rupture occurs in the elastoplastic phase, this behaviour can only be analysed using the finite element method (FEM), (Argüelles, Arriaga, \& Martínez, 2003).

Although there are many studies combining FEM techniques and the theory of strength of materials to predict the ultimate capacity of solid sawn timber, only a few authors (Cramer, Shi, \& McDonald, 1996), (Pellicane \& Franco, 1994a,b), (Itagaki, Mihashi, Ninomiya, Yoshida, \& Esashi, 1999), among
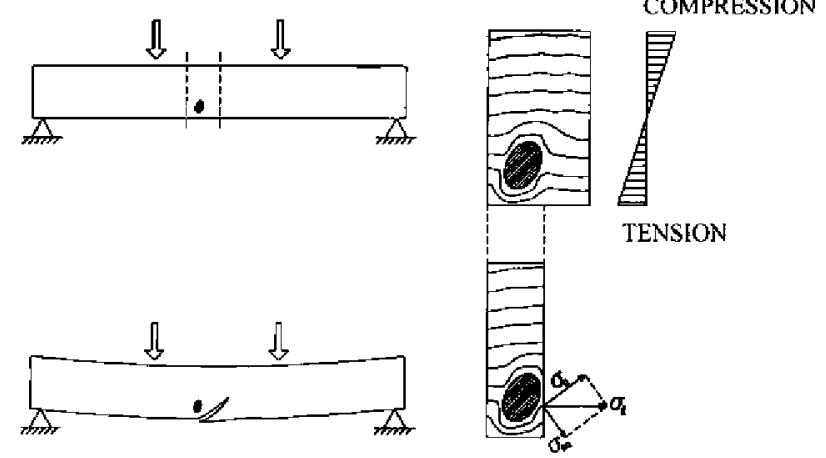

Fig. 1 - Influence of the presence of knots in the rupture of bending timber beams (from Argüelles et al., 2003). others, have considered the influence of the presence of knots and the deviation of grain in timber.

The simplest way to simulate knots is to consider them as simple holes. One example is the numerical simulation of sawn recycled timbers containing fastener holes caused by screws. Williams, Fridley, Cofer, and Falk (2000) used FEM to model the timbers as an anisotroic material in order to predict failure load and stress concentrations around the hole. It has been suggested that timber behaviour in grading and strength ratio calculations is affected in similar ways whether the singularity is a knot or a hole (Williams et al., 2000).

However, when sawn timber contains knots instead of holes, grain deviation around the knot plays an important role in stress distribution and location of failure. Pellicane and Franco (1994a,b) developed a model to predict strength and failure location in wooden poles using a flow-grain analogy, based on the theoretical laminar flow behaviour of a fluid around an elliptic obstruction, in order to simulate the local grain deviation.

Several failure criteria have been considered by different authors in order to predict ultimate failure strength, such as the Tsai-Wu strength theory for anisotropic materials (Tsai \& Wu, 1971); Hill's yield criterion (Hill, 1948) as used by Guan and Zhu (2008) for predicting the failure of composite I-beams of oriented strand board (OSB) and sawn timber with holes and the Norris failure criterion (Norris, 1962) used by Danielsson and Gustafsson (2010) to predict the strength of glulam beams with holes.

Thus, it can be seen that the modelling of a beam with knots differs from that of a beam with holes. Therefore, the objective of this paper is to describe a finite element model to simulate the behaviour of timber beams with knots and to predict failure load and the location of the rupture, in relation to size and position of knot and grain deviation around the 


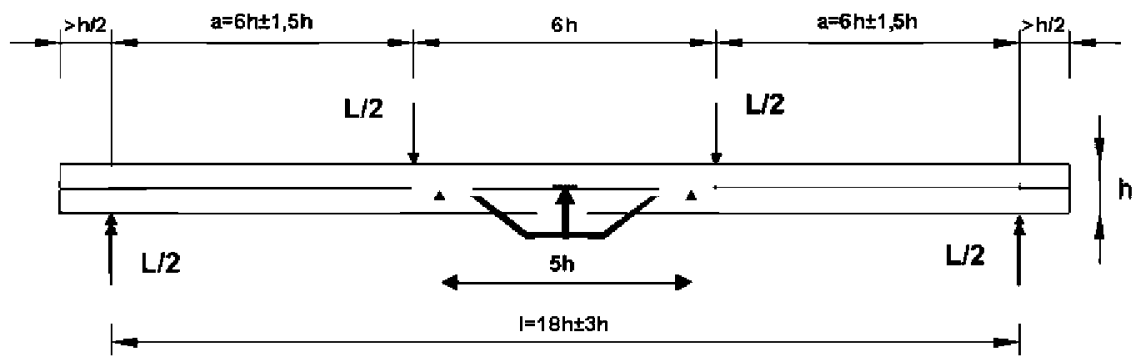

Fig. 2 - Bending stresses in a rectangular cross-section with different modulus of elasticity in compression and tension.

Table 1 - Ultimate stress in tension and compression parallel to the grain in P. sylvestris L. (Argüelles Bustillo, 1994).

\begin{tabular}{lllll} 
Tension $f_{t, 0, u}$ & & & \multicolumn{2}{c}{ Compression $f_{c, 0, u}$} \\
\cline { 5 - 5 } $\begin{array}{l}\text { Mean value } \\
\left(\mathrm{N} \mathrm{mm}^{-2}\right)\end{array}$ & $\operatorname{CoV}(\%)$ & & $\begin{array}{l}\text { Mean value } \\
\left(\mathrm{N} \mathrm{mm}^{-2}\right)\end{array}$ & $\operatorname{CoV}(\%)$ \\
\hline 89.05 & 30 & 57.11 & 11 \\
\hline
\end{tabular}

knot. To this end, different FEM models of knots were analysed and compared to the experimental behaviour of timbers to determine the best predictor.

\section{Material and methods}

\subsection{Material tested}

Ten $3000 \mathrm{~mm}$ long pieces of sawn timber of redwood pine (Pinus sylvestris L.) with a cross-section of $45 \times 145 \mathrm{~mm}$ were used to validate the model. Tangentially cut pieces were selected which showed through knots (i.e. face to face knots) in order to simplify the subsequent simulation by FEM. The knot diameter of central third of the length of the piece was between 28.5 and $43.7 \mathrm{~mm}$.

The planed pieces were conditioned at $20 \pm 2{ }^{\circ} \mathrm{C}$ temperature and $80 \pm 5 \%$ air relative humidity. At the end of this process, the final dimensions of cross-section were $43 \times 142 \mathrm{~mm}$ and the mean moisture content of the timber was $20.7 \%$ (ranging from 19.5 to $27 \%$ ); this moisture content was selected in order to minimise the effect of drying fissures on the final mechanical results. The mean density value was $556 \mathrm{~kg} \mathrm{~m}^{-3}$ (ranging from 498 to $664 \mathrm{~kg} \mathrm{~m}^{-3}$ ).

\subsection{Mechanical properties}

The local elasticity modulus in bending $\left(E_{m}\right)$ and bending strength $\left(f_{m}\right)$ were obtained according to the EN 408 standard (2003). The test piece was simply supported with a span of 18 times its beam depth and two loads were applied symmetrically at equidistant points, (Fig. 2). The local elasticity modulus is free of shear effects and is obtained in the central part of the beam where the knots causing the failure are located. Therefore, this elasticity modulus is more useful for the FEM simulation of this portion of the beam than the global elasticity modulus.

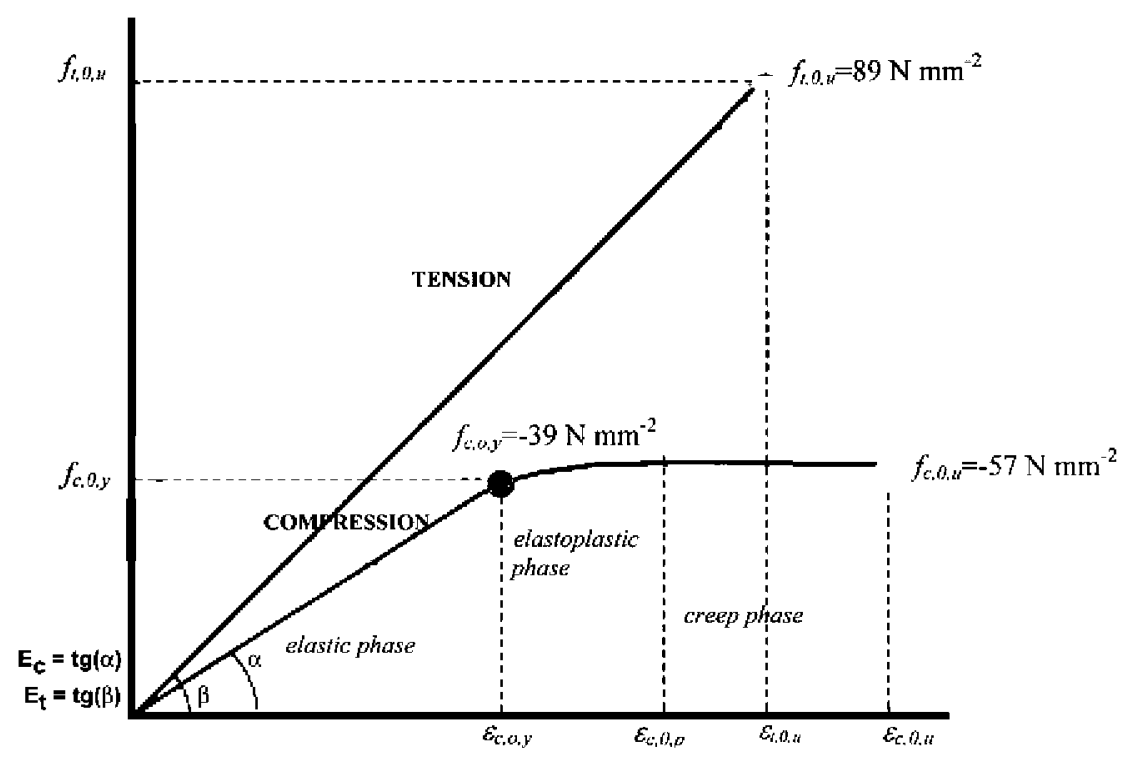

Fig. 3 - Arrangement for bending test according to EN 408 (2003). 
Table 2 - Relationship between stress level and modulus of elasticity in compression parallel to the grain

\section{(Argüelles Bustillo, 1994).}

\begin{tabular}{lc} 
Stress $\sigma_{c, 0}\left(\mathrm{~N} \mathrm{~mm}^{-2}\right)$ & $E_{c, 0}\left(\mathrm{~N} \mathrm{~mm}^{-2}\right)$ \\
\hline$\sigma<-57$ & 10 \\
$-57 \leq \sigma<-55$ & 500 \\
$-55 \leq \sigma<-52$ & 1100 \\
$-52 \leq \sigma<-50$ & 2000 \\
$-50 \leq \sigma<-45$ & 2700 \\
$-45 \leq \sigma<-41$ & 3300 \\
$-41 \leq \sigma<-39$ & 4200 \\
$-39 \leq \sigma<0$ & 8100 \\
\hline
\end{tabular}

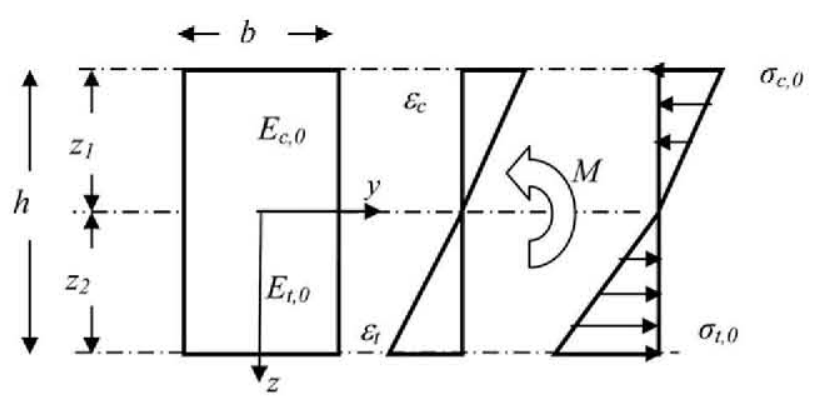

Fig. 4 - Stress-strain law for compression parallel to the grain.

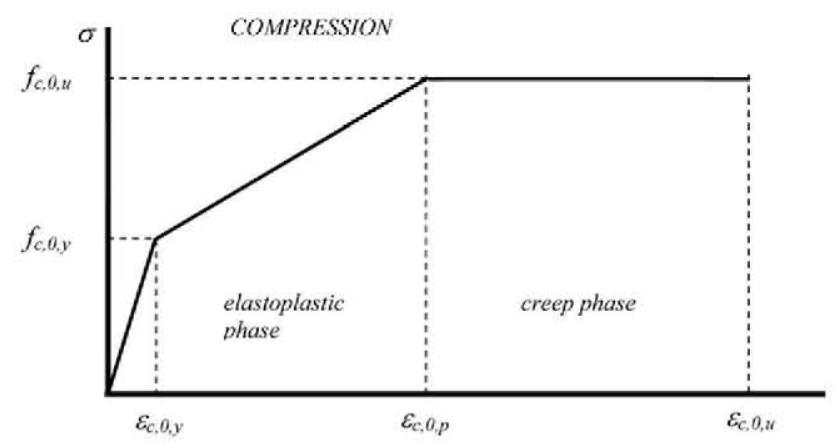

Fig. 5 - Simplified stress-strain behaviour of timber in compression according to Hill (1948)

\subsection{Numerical simulation}

\subsubsection{General}

The four points bending test was simulated using FEM with the software ANSYS 12.0, ANSYS, Inc., Canonsburg, USA, and several models for knots were considered in order to predict the ultimate load. The orthotropic and elastoplastic behaviour law of timber was modelled using APDL language, with the stiffness properties of redwood pine taking into account the curve zone of stress-strain in the compression diagram.

\subsubsection{Stiffness properties}

The elastic constants adopted in the FEM analysis were those from previous experimental work on small clear specimens of the same species (Argüelles Bustillo, 1994). In that work 82 specimens of $10 \times 30 \times 250 \mathrm{~mm}$ were tested in tension parallel to the grain obtaining an average value of the ultimate stress of $89.5 \mathrm{~N} \mathrm{~mm}^{-2}$; further 157 specimens of $20 \times 20 \times 60 \mathrm{~mm}$ were tested in compression parallel to the grain obtaining an average value of $57 \mathrm{~N} \mathrm{~mm}^{-2}$ for the rupture stress, Table 1 . The stress-strain law for tension parallel to the grain was considered as elastic and linear until rupture. The stress-strain law for compression parallel to the grain was obtained in 34 of the 157 specimens tested in compression, resulting in an initially linear and then curved law, (Fig. 3). From these results a mean value of modulus of elasticity in compression parallel to the grain of $8096 \mathrm{~N} \mathrm{~mm}^{-2}$ was obtained for the linear phase and the mean value of the yield stress was $39 \mathrm{~N} \mathrm{~mm}^{-2}$ Table 2 shows the variation of the modulus of elasticity depending on the level of compression.

The modulus of elasticity obtained by test (see section 2.2) is the local bending elasticity modulus in bending parallel to the grain (Em), also known as bending apparent modulus; in actual fact the material has a higher modulus of elasticity in tension and a lower modulus in compression (Bach, 1920) and (Bach \& Bauman, 1928). In a rectangular cross-section subjected to a bending moment $\mathrm{M}$, with different modulus of elasticity for compression and tension $\left(E_{c, 0}\right.$ and $\left.E_{t, 0}\right)$ and assuming the Bernoulli hypothesis ( $\epsilon=k z$ ), (Fig. 4) from the equilibrium of moments.

$$
\begin{aligned}
M & =\int_{z_{2}}^{0} \sigma_{t, 0} \cdot z \cdot b \cdot d z+\int_{0}^{z_{1}} \sigma_{c, 0} \cdot z \cdot b \cdot d z=k \cdot I_{y} \cdot \frac{4 \cdot E_{t, 0} \cdot E_{c, 0}}{\left(\sqrt{E_{t, 0}}+\sqrt{E_{c, 0}}\right)^{2}} \\
& =k \cdot I_{y} \cdot E_{m}
\end{aligned}
$$

where:

$$
\begin{aligned}
& \sigma_{t, 0}=\epsilon_{t} \cdot E_{t, 0}=k \cdot z \cdot E_{t, 0} \\
& \sigma_{c, 0}=\epsilon_{c} \cdot E_{c, 0}=k \cdot z \cdot E_{c, 0}
\end{aligned}
$$

The symbols $z_{1}$ and $z_{2}$ are the heights corresponding to the compression and tension parts of the cross-section,
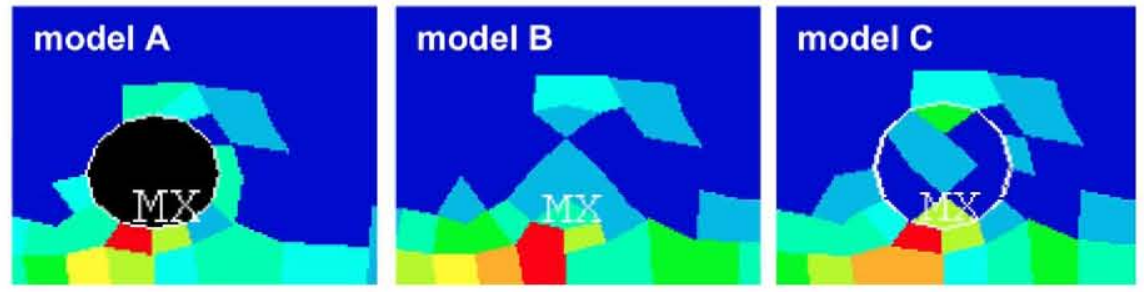

Fig. 6 - Detail of the numerical simulation of knots as holes (a), adherent knots (b) and partially adherent knots (c). 

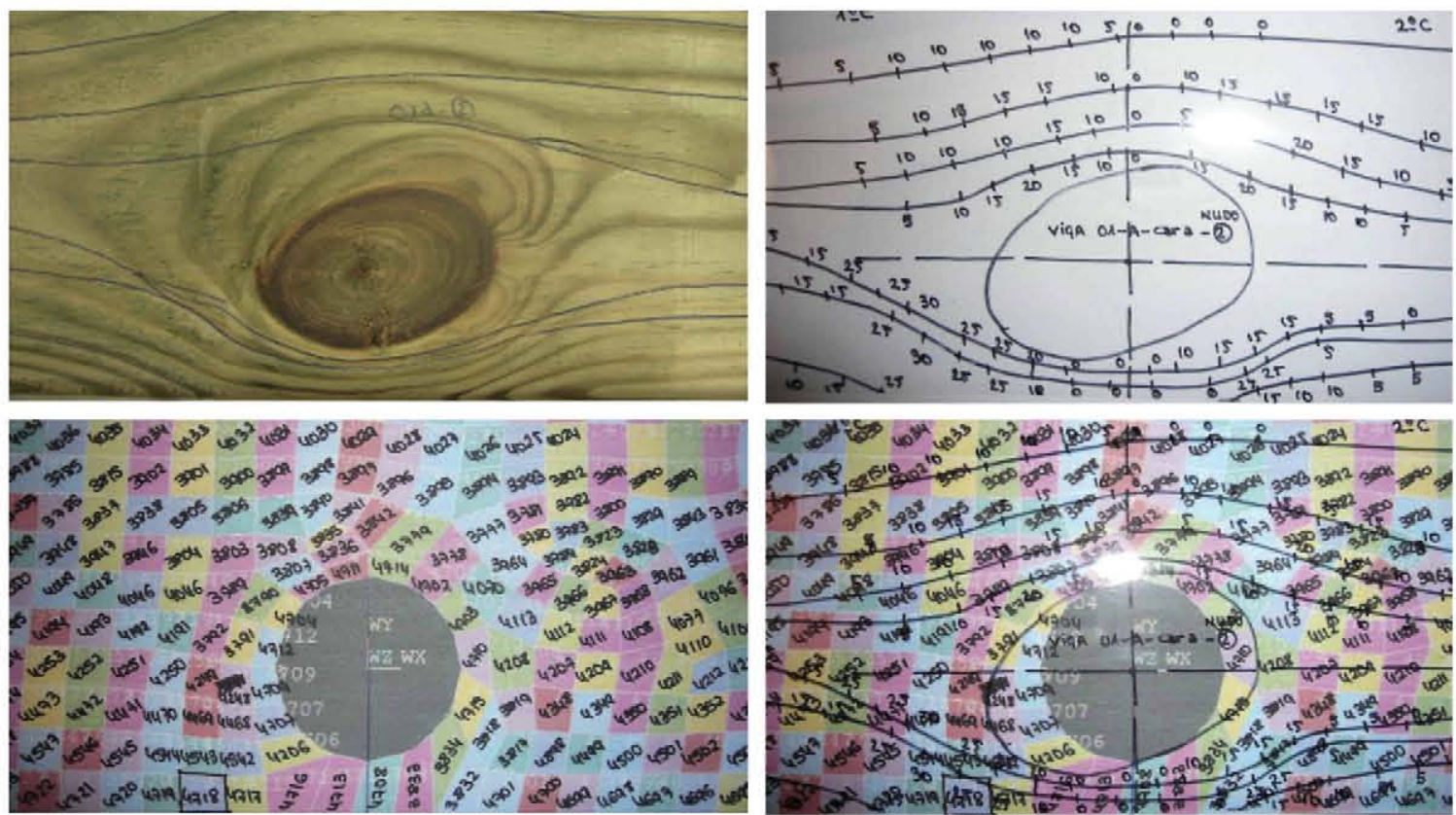

Fig. 7 - Measurement of slope of grain around the knot and the introduction in the FEM model.

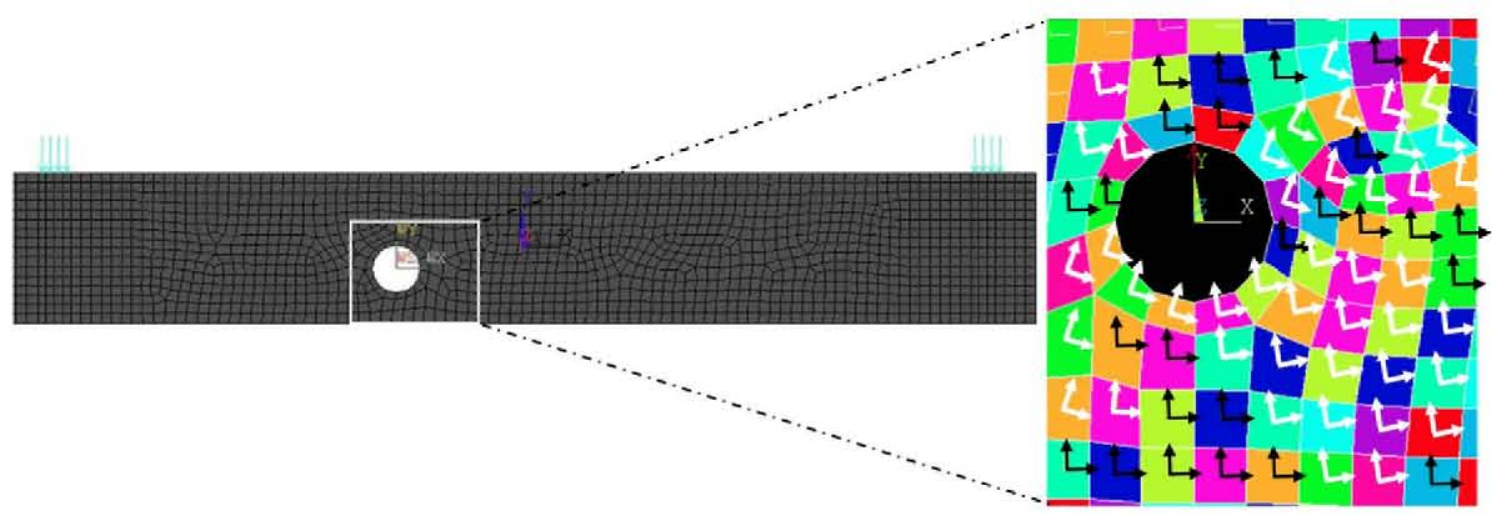

Fig. 8 - Simulation of slope of grain: local axis of main direction in each element of the mesh around knots.

respectively; and $k$ is the curvature of the section. Thus, the apparent modulus of elasticity in bending $\left(E_{m}\right)$ can be expressed as:

$E_{m}=\frac{4 \cdot E_{t, 0} \cdot E_{c, 0}}{\left(\sqrt{E_{t, 0}}+\sqrt{E_{c, 0}}\right)^{2}}$

The relationship $k_{E}=E_{t, 0} / E_{c, 0}$ can be estimated from the equations given in Regles C.B. 71 (1984), where the modulus of elasticity for tension and compression are proportional to the square root of tension and compression strength. For clear timber with tension and compression strengths of 89 and $57 \mathrm{~N} \mathrm{~mm}^{-2}$ respectively, the value of $k_{E}$ is approximately equal to $1.2(89 / 57)^{0.5}$. Assuming the relationship $k_{E}=1.2$, it is possible to deduce the modulus of elasticity in compression for each piece tested in bending:

$E_{c, 0}=E_{m} \cdot \frac{1+k_{E}+2 \sqrt{k_{E}}}{4 \cdot k_{E}}=0.915 \cdot E_{m}$
The value of shear modulus of elasticity used was $G=E_{m} /$ $16\left(\mathrm{~N} \mathrm{~mm}^{-2}\right)$; the value of modulus of elasticity perpendicular to the grain, $E_{90}=E_{m} / 30\left(\mathrm{~N} \mathrm{~mm}^{-2}\right)$ as defined for coniferous species in EN 338 (2010) and a Poisson's ratio of $v=0.4$. The quadratic failure criterion is not very sensitive to variation of stiffness properties such as shear modulus (Haasbroek \& Pretorius, 1994) or modulus of elasticity perpendicular to the grain.

Table 3 - Ultimate stresses in tension and compression parallel to the grain and shear for P. sylvestris L. adopted in FEM model.

\begin{tabular}{ll} 
Tension parallel to the grain $\left(\mathrm{N} \mathrm{mm}^{-2}\right)$ & $f_{t, 0, u}=89$ \\
Compression parallel to the grain $\left(\mathrm{N} \mathrm{mm}^{-2}\right)$ & $f_{c, 0, u}=57$ \\
Yield stress in compression parallel & $f_{c, 0, y}=39$ \\
to the grain $\left(\mathrm{N} \mathrm{mm}^{-2}\right)$ & \\
Tension perpendicular to the grain $\left(\mathrm{N} \mathrm{mm}^{-2}\right)$ & $f_{t, 90, u}=10$ \\
Shear $\left(\mathrm{N} \mathrm{mm}^{-2}\right)$ & $f_{v, u}=14$ \\
Compression perpendicular to the grain $\left(\mathrm{N} \mathrm{mm}^{-2}\right)$ & $f_{c, 90, u}=7$ \\
\hline
\end{tabular}




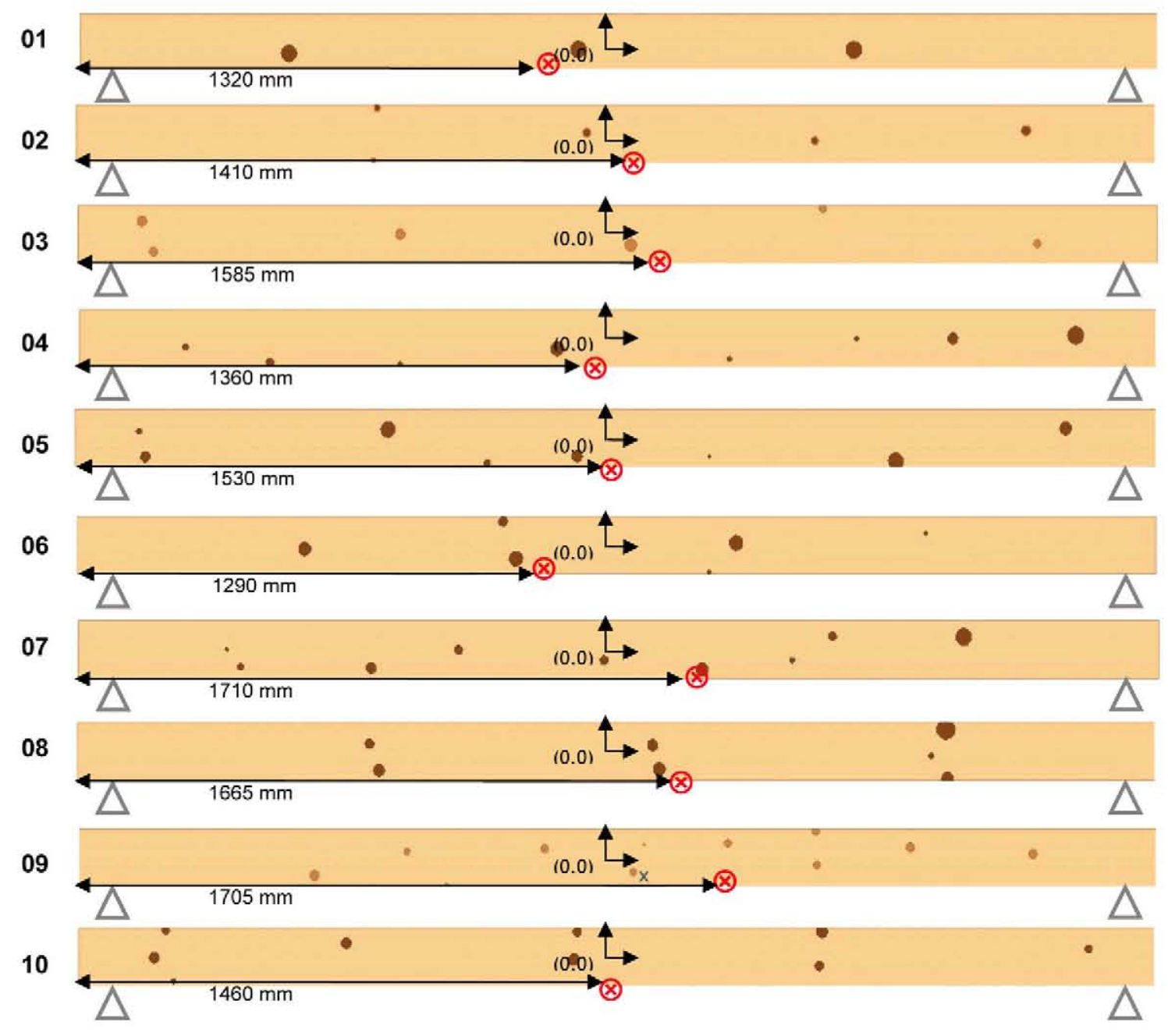

Fig. 9 - Position of rupture section.

\subsubsection{Test simulation}

The geometry of the beams was created by rectangular areas taking into account the key points of the four-point bending test. Steel plates were modelled in the supports in order to avoid local stress concentrations and the knots were drawn with a circular geometry. Since all loads and displacements were in-plane, 4-node plane stress quadrilateral elements (Plane 42) from the ANSYS library were used with as uniform

\section{Table 4 - Results of rupture strength $(\mathrm{kN})$, modulus of rupture $\left(\mathrm{N} \mathrm{mm}^{-2}\right)$ and moduli of elasticity $\left(\mathrm{N} \mathrm{mm}^{-2}\right)$ of bending}

\section{tested beams.}

\begin{tabular}{|c|c|c|c|c|c|c|c|}
\hline $\begin{array}{l}\text { Beam } \\
\text { number }\end{array}$ & $\begin{array}{c}\text { Maximum } \\
\text { load, } \\
F_{\max }(\mathrm{kN})\end{array}$ & $\begin{array}{c}\text { Modulus of } \\
\text { rupture, } \\
f_{m}\left(\mathrm{~N} \mathrm{~mm}^{-2}\right)\end{array}$ & $\begin{array}{l}\text { Local modulus } \\
\text { of elasticity, } \\
E_{m}\left(\mathrm{~N} \mathrm{~mm}^{-2}\right)\end{array}$ & $\begin{array}{l}\text { Modulus of } \\
\text { elasticity in } \\
\text { tension parallel } \\
\text { to the grain, } \\
E_{t, 0}\left(\mathrm{~N} \mathrm{~mm}^{-2}\right)\end{array}$ & $\begin{array}{c}\text { Modulus of } \\
\text { elasticity in } \\
\text { compression } \\
\text { parallel to the } \\
\text { grain, } E_{\mathrm{c}, 0}\left(\mathrm{~N} \mathrm{~mm}^{-2}\right)\end{array}$ & $\begin{array}{c}\text { Shear } \\
\text { modulus } \\
\text { of elasticity, } \\
G\left(\mathrm{~N} \mathrm{~mm}^{-2}\right)\end{array}$ & $\begin{array}{l}\text { Modulus of } \\
\text { elasticity } \\
\text { perpendicular } \\
\text { to the grain, } \\
E_{90}\left(\mathrm{~N} \mathrm{~mm}^{-2}\right)\end{array}$ \\
\hline 01 & 7.9 & 35.4 & 9737 & 10690 & 8908 & 609 & 325 \\
\hline 02 & 15.9 & 48.4 & 9803 & 10762 & 8968 & 613 & 327 \\
\hline 03 & 9.1 & 27.2 & 8389 & 9209 & 7674 & 524 & 280 \\
\hline 04 & 10.4 & 44.5 & 12025 & 13200 & 11000 & 752 & 401 \\
\hline 05 & 4.8 & 38.8 & 10173 & 11167 & 9306 & 636 & 339 \\
\hline 06 & 11.9 & 37.6 & 8353 & 9170 & 7642 & 522 & 278 \\
\hline 07 & 5.9 & 22.7 & 11290 & 12392 & 10327 & 706 & 376 \\
\hline 08 & 8.3 & 25.2 & 9242 & 10146 & 8455 & 578 & 308 \\
\hline 09 & 16.8 & 53.1 & 14067 & 15442 & 12868 & 879 & 469 \\
\hline 10 & 17.1 & 51.0 & 12705 & 13948 & 11623 & 794 & 424 \\
\hline
\end{tabular}


Table 5 - Results of maximum bending load of numerical simulated beams by knots models A, B and C.

\begin{tabular}{|c|c|c|c|}
\hline Beam & Model of knot & $F_{\max }(\mathrm{kN})$ & Error (\%) \\
\hline \multirow[t]{3}{*}{01} & model A & 8.4 & 5.8 \\
\hline & model B & 9.5 & 16.6 \\
\hline & model C & 9.1 & 12.9 \\
\hline 02 & - & 21.1 & 24.6 \\
\hline \multirow[t]{3}{*}{03} & model A & 9.8 & 7.5 \\
\hline & model B & 10.8 & 15.7 \\
\hline & model C & 10.7 & 14.8 \\
\hline \multirow[t]{3}{*}{04} & model A & 11.6 & 9.7 \\
\hline & model B & 18.4 & 43.3 \\
\hline & model C & 12.1 & 13.6 \\
\hline \multirow[t]{3}{*}{05} & model A & 5.0 & 5.3 \\
\hline & model B & 7.1 & 32.6 \\
\hline & model C & 5.6 & 15.3 \\
\hline \multirow[t]{3}{*}{06} & model A & 11.0 & 7.5 \\
\hline & model B & 11.8 & 0.8 \\
\hline & model C & 11.5 & 2.9 \\
\hline \multirow[t]{3}{*}{07} & model A & 6.0 & 2.5 \\
\hline & model B & 12.5 & 52.8 \\
\hline & model C & 6.7 & 2.8 \\
\hline \multirow[t]{3}{*}{08} & model A & 7.7 & 7.5 \\
\hline & model B & 12.4 & 67.5 \\
\hline & model C & 8.1 & 7.9 \\
\hline 09 & - & 19.5 & 13.8 \\
\hline 10 & - & 20.5 & 16.6 \\
\hline
\end{tabular}

a meshing as possible. To avoid concentrated stresses, load was applied as a press load on a line in the beam that transmits the load to nodes of elements, i.e.: Press load = concentrated point load/line length.
The plastic law available in ANSYS is the yield criterion for orthotropic materials introduced by Hill (1948), where the elastic and elastoplastic zone are considered as two straight lines with different slope (Fig. 5). Therefore, in order to achieve a more accurate prediction of the ultimate bending capacity of each tested beam, a "load-stepping" method was developed in which the modulus of elasticity of the compressed elements was modified depending on the stress reached, in accordance with the relationship indicated in Table 2.

\subsubsection{Simulation of defects}

The knots were modelled as face to face knots incorporating the material properties of the wood in the perpendicular to the grain direction and taking into account local grain deviation. Three models were developed to characterise the knots: model A: knots considered as holes in the beam; model B: adherent knots, where there is structural continuity of knot material and the rest of the beam material; and model C: partial contact between knot and beam, artificially simulated by means of a contact spring with a friction value of 0.6 between the two materials, as used by Villar, Guaita, Vidal, and Arriaga (2007), (Fig.6).

The size and position of knots with respect to the beam edge and the local grain deviation were marked in the test beams. In addition, this information was drawn onto a transparent sheet as a record (Fig. 7). Since the mesh of each beam varies depending on the size and location of the knot, an adjustment of the local coordinate system of each element was necessary in order to assign the corresponding local deviation of grain (Fig. 8). Furthermore, the general slope of grain of each beam was taken into consideration.

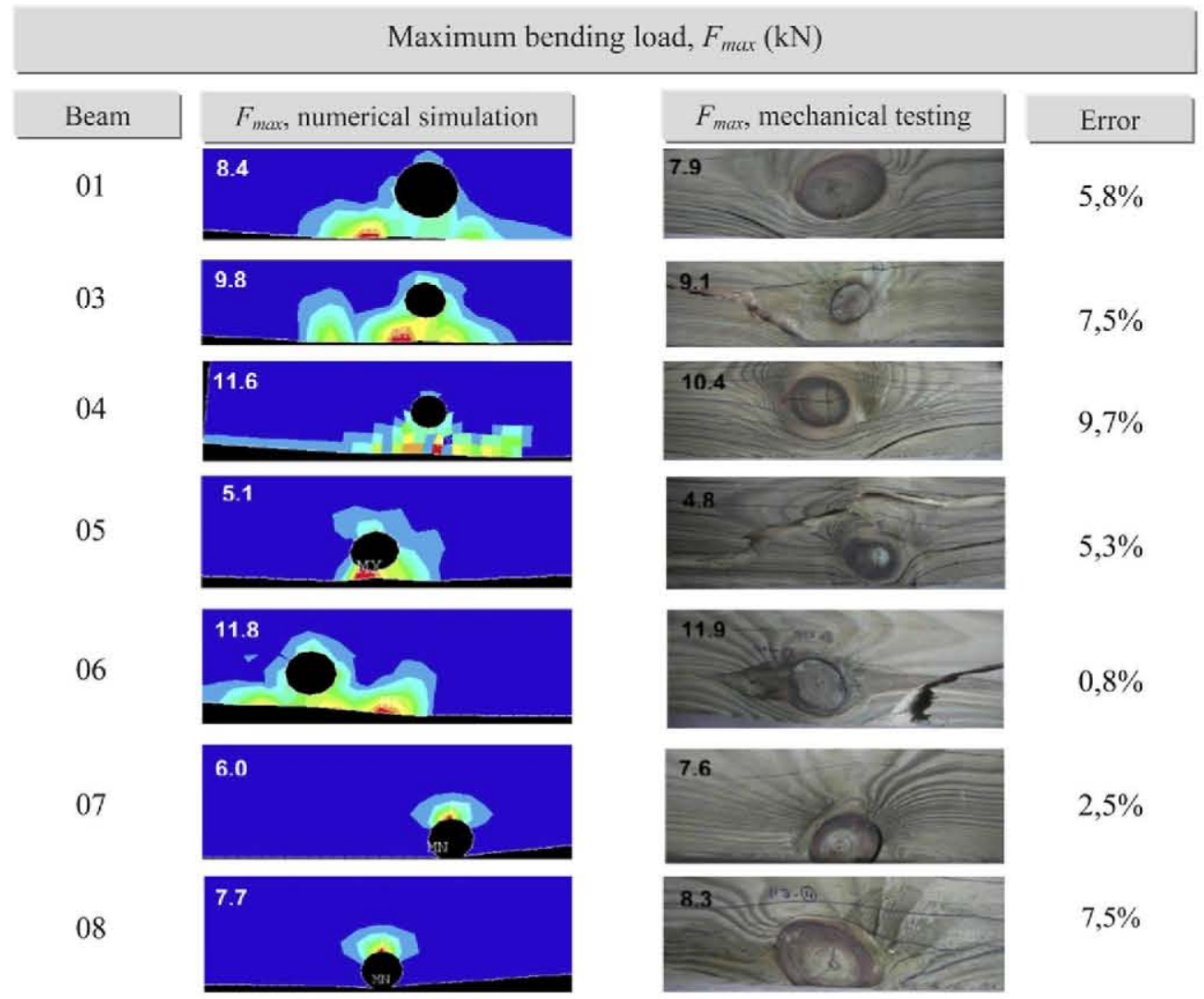

Fig. 10 - Experimental test results vs. numerical simulation for maximum bending load. 


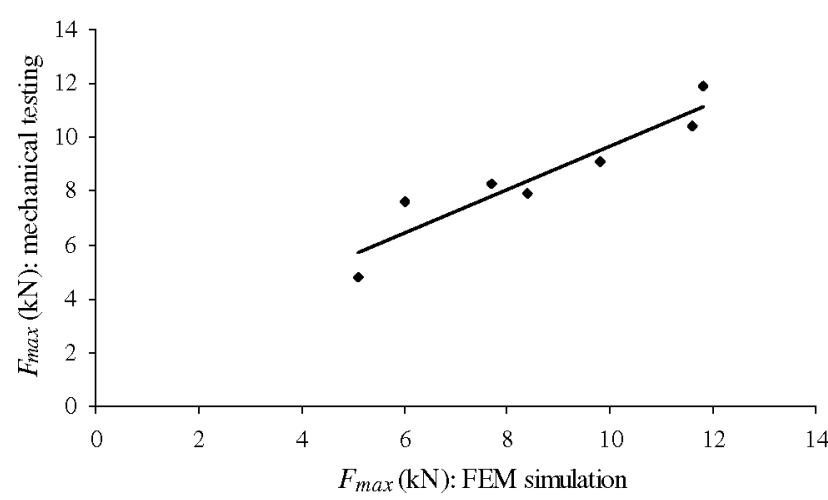

Fig. 11 - Correlation between maximum bending load from mechanical testing and numerical simulation using FEM model.

\subsubsection{Failure criterion}

The load-stepping method developed in ANSYS is automatic and finishes when one element of meshing reaches the value of 1 in the quadratic failure criterion which, according to Aicher and Klöck (2001) can be perceived as a special case of the Tsai-Wu (Tsai \& Wu, 1971) tensor polynomial approach. This criterion establishes the relationship between stress and strength by combining the parallel to the grain, the perpendicular to the grain and shear stresses, according to tension or compression elements in the beam. The compression failure of the beam is determined by Eq. (6) and the tension rupture of the beam by Eq. (7).

$\left(\frac{\sigma_{c, 0}}{f_{c, 0, u}}\right)^{2}+\left(\frac{\sigma_{c, 90}}{f_{c, 90, u}}\right)^{2}+\left(\frac{\tau}{f_{v, u}}\right)^{2} \leq 1$

$\left(\frac{\sigma_{t, 0}}{f_{t, 0, u}}\right)^{2}+\left(\frac{\sigma_{t, 90}}{f_{t, 90, u}}\right)^{2}+\left(\frac{\tau}{f_{v, u}}\right)^{2} \leq 1$

where $\sigma_{t, 0}$ is the applied stress in tension parallel to the grain; $f_{t, 0, u}$ is the ultimate stress in tension parallel to the grain; $\sigma_{t, 90}$ is the applied stress in tension perpendicular to the grain; $f_{t, 90, u}$ is the ultimate stress in tension perpendicular to the grain; $\tau$ is the applied shear stress; $f_{v, u}$ is the ultimate stress in shear; $\sigma_{\mathrm{c}, 0}$ is the applied stress in compression parallel to the grain; $f_{c, 0, u}$ is the ultimate stress in compression parallel to the grain; $\sigma_{c, 90}$ is the applied stress in compression perpendicular to the grain and $f_{c, 90, u}$ is the ultimate stress in compression perpendicular to the grain.

Table 3 shows the values adopted for quadratic failure criterion in the finite element model, where the ultimate stress in tension and compression parallel to the grain were obtained from previous experimental tests conducted by Argüelles Bustillo (1994). The other values were chosen so that the numerical simulation provided a good fit with the experimental results. Therefore, obviously some of the values adopted $\left(f_{c, 90, u}\right.$ and $\left.f_{v, u}\right)$ were far from those obtained with small clear specimen tests.

Ultimate load and failure position data, obtained from numerical simulation, were recorded for each beam and for each knot model as defined above, for comparison with experimental results.

\section{Results and discussion}

\subsection{Results of mechanical testing}

Of the ten beams tested, seven broke due to the influence of a knot, positioned in the tension side of the beam. The remainder (beams number 02,09 and 10) broke as a result of a tension parallel to the grain, without the influence of the presence of knots. The position of failure in the beams, in relation to the position of knots, was recorded for each specimen, (Fig. 9).

The results of the maximum load $\left(F_{\max }\right)$, the modulus of rupture $\left(f_{m}\right)$ and the local modulus of elasticity $\left(E_{m}\right)$ for each tested beam are shown in Table 4. From these data, in accordance with Eq. (2) and assuming the relationship $E_{t, 0} / E_{c, 0}=1.2$, the modulus of elasticity in tension and compression parallel to the grain were calculated. Shear modulus and modulus of elasticity perpendicular to the grain were deduced from the relationships explained in Section 2.3.2. These stiffness values were introduced in each finite element model.

\subsection{Results of the numerical simulation}

The results of maximum load $\left(F_{\max }\right)$ were obtained by the finite element method. Table 5 presents the results for the seven beams that broke due to the influence of a knot, for the three models of knots (model A, B and C) and the three beams that broke without the influence of the presence of knots.

Maximum load and positions of rupture were analysed for the three models of knots. Model A, where the knot considered as a hole in the beam with local grain deviation around it, was the best predictor of the maximum load of rupture for both cylindrical and face to face knots when positioned in the tension side of the beam. The rupture was produced in accordance with the quadratic failure criterion.

The values of maximum bending load in numerical simulation by FEM were very similar to the experimental results, with an error in the estimation of load capacity of less than $9.7 \%$, (Fig.10). There was a strong correlation between the numerical prediction of maximum bending load and the experimental results, coefficient of determination $\left(r^{2}\right)=0.88$, (Fig. 11).

In the three pieces with failure unrelated to knots (specimens 2, 9 and 10), the theoretical maximum bending stress (bending moment $(M) /$ section modulus(W)) was 52, 65 and $55 \mathrm{~N} \mathrm{~mm}^{-2}$, respectively.

\section{Conclusions}

A new tool has been developed in order to simulate the behaviour of bending timber beams and to predict the fracture load of these beams according to the position and size of knots and the local grain deviation around them. The model created by FEM incorporated the orthotropic and elastoplastic behaviour of the timber in compression, with different modulus of elasticity in compression and in tension. It was demonstrated using sawn coniferous timber beams with constant bending moment and a cross-section of 
$45 \times 145 \mathrm{~mm}$, which had knots approximately perpendicular to the face of the beams.

Three types of models of knots were studied: knot as hole (model A), adherent knot (model B) and partially adherent knot (model C). The model using knots as a hole (model A) was found to be the most representative of behaviour when the knot was located in the tension side of the beam. In this scenario, the failure is produced by the influence of the knot, in a combination with tension parallel and perpendicular to the grain stresses and shear stress. The quadratic failure criterion does not accurately predict the maximum load in bending from the critical values of strength obtained from tests on clear specimens. It is also necessary to adjust the values of shear and tension perpendicular to the grain stresses for good predictions.

However, a comparison of the results of the analytical model to those from experiments when knots were located in the tension side of the beam, demonstrated that the FEM model developed could generate accurate results, with an estimation error $<9.7 \%$ and an $r^{2}=0.88$.

The heterogeneity in mechanical properties of timber is reflected in the three beams that broke due to tension parallel to the grain failure, without the influence of knots, (pieces 2, 9 and 10), taking a value of 0 the terms corresponding to tension perpendicular to the grain and shear in quadratic failure criterion. For this reason, the quadratic failure criterion is less accurate in predicting the breaking load of beams which are free of knots in the tension side.

\section{Acknowledgements}

This work was funded by the Spanish government, Plan Nacional del Ministerio de Ciencia y Tecnología, within the framework of research project AGL2009-11331, co-funded by the European Regional Development Fund (ERDF) and by the Galician government Xunta de Galicia, within the framework of research project 09MDS016291PR.

\section{REF E RE N C E S}

Aicher, S., \& Klöck, W. (2001). Linear versus quadratic failure criteria for inplane loaded wood based panels. Otto Graf Journal, 12.

Argüelles, R., Arriaga, F., \& Martínez, J. J. (2003). Estructuras de Madera. Diseño y Cálculo. [Timber structures. Design and Calculus] (2nd ed.). Madrid, Spain: AITIM. Asociación de Investigación Técnica de las Industrias de la Madera y Corcho.
Argüelles Bustillo, R. (1994). Predicción con Simulación Animada del Comportamiento de Piezas de Madera, [Animated prediction of the behavior of wood specimens] PhD Thesis. Escuela Técnica Superior de Ingenieros de Montes, Universidad Politécnica de Madrid, Spain.

Bach, C. (1920). Elastizität und Festigkeit. Berlin: Verlag von Julios Springer.

Bach, C., \& Bauman, R. (1928). Elasticità e resistenza dei materiali. Ulrico Hoepli, Milano: Prima traduzione italiana.

CEN. (2010). Structural timber. Strength classes. EN 338. Brussels, Belgium: European Committee for Standardization.

CEN. (2003). Timber Structures. Structural timber and glued laminated timber. Determination of some physical and mechanical properties. EN 408. Brussels, Belgium: European Committee for Standardization.

Cramer, S., Shi, Y., \& McDonald, K. (1996). Fracture modeling of lumber containing multiple knots. In. Proceedings of the international wood engineering conference, Vol. 4 (pp. 288-294). New Orleans, L.A: Lousiana State University.

Danielsson, H., \& Gustafsson, P. J. (2010). A probabilistic fracture mechanics method and strength analysis of glulam beams with holes. European Journal of Wood and Wood Products. doi:10 1007/s00107-010-0475-1.

Guan, Z. W., \& Zhu, E. C. (2008). Finite element modelling of anisotropic elasto/plastic timber composite beams with openings. Engineering Structures. doi:10.1016/j.engstruct. 2008. 09.007.

Haasbroek, D. F., \& Pretorius, L. (1994). Orthotropic failure criterion for timber. R\&D Journal, 10(1), 1-6.

Hill, R. (1948). A theory of the yielding and plastic flow of anisotropic materials. Proceedings of the Royal Society of London. Series A, 1-281.

Itagaki, N., Mihashi, H., Ninomiya, S., Yoshida, N., \& Esashi, T. (1999). Influence of knots on tensile strength of sugi lamina. Mokuzai Gakkaishi, 45(5), 367-374.

Norris, C. B. (1962). Strength of orthotropic materials subjected to combined stresses. N. 1816. USDA. Madison, Wisconsin: Forest Products Laboratory.

Pellicane, P. J., \& Franco, N. (1994a). Modelling wood pole failure. 1. Finite element stress analysis. Wood Science and Technology, 28(3), 219-228.

Pellicane, P. J., \& Franco, N. (1994b). Modelling wood pole failure. 2. Material and geometric considerations. Wood Science and Technology, 28(4), 261-274.

Regles C.B 71. (1984). Regles de calcul et de conception des charpentes en bois. DTU. Paris: Eyrolles.

Tsai, S., \& Wu, E. (1971). A general theory of strength for anisotropic materials. Journal of Composite Materials, (5), 58-80.

Villar, J. R., Guaita, M., Vidal, P., \& Arriaga, F. (2007). Analysis of the stress State at the Cogging Joint in timber Structures. Biosystems Engineering, 96(1), 79-90.

Williams, J. M., Fridley, K. J., Cofer, W. F., \& Falk, R. H. (2000). Failure modelling of sawn lumber with a fastener hole. Finite Element in Analysis and Design, 36(1), 83-98. 